AC 2004-1305: USING INFORMATION TECHNOLOGY TO FACILITATE STUDENT LEARNING

Akram Al-Rawi, McKendree University

Azzedine Lansari,

Faouzi Bouslama, Université Laval 


\title{
Using Technology to Facilitate Student Learning in Information Systems
}

\author{
Azzedine Lansari, Akram Al-Rawi, and Faouzi Bouslama \\ College of Information Systems, Zayed University \\ P. O. Box 4783, Abu Dhabi, UAE
}

\begin{abstract}
The use of technology in education has become critical in today's academic institutions. Colleges and universities worldwide have seen a dramatic increase in the use of technology in the classroom. Zayed University, an academic institution in the United Arab Emirates, has recently built an environment where learning is the main focus. English is used as the language of instruction, however as it is not the students' native language they sometimes have difficulties understanding the course content. Furthermore, students are often too shy to ask questions during class time making it difficult for the instructor to monitor comprehension. To address these issues, instructors in the College of Information Systems are using technology as a basis to create an environment that encourages and facilitates student learning. This environment includes a wired laptop-based campus, an IS curriculum that is driven by learning outcomes, electronic portfolios, and the building of learning communities. Technology facilitates student learning in many ways. As an alternative to face-to face communication, students can use a variety of tools such as electronic mail, Blackboard, Internet and the Intranet, and shared network drives for communication and information access and exchange. Moreover, students are required to develop an electronic portfolio, which includes their most important learning experiences. Using technology, faculty can access and assess student portfolios and provide feedback and guidance online. In addition, the wired campus allows students to create learning communities where ideas, information and knowledge are shared. Faculty can join these communities to integrate multiple learning perspectives as well as provide guidance and learning structures where reflection and critical thinking are encouraged. This new learning environment has resulted in a less inhibited student body where technology is used extensively to interact with other students, faculty members as well as the outside community to seek and create knowledge and ultimately become independent lifelong learners.
\end{abstract}

\section{Introduction}

Universities in the USA and worldwide are taking a critical look at their educational systems. A recent US national panel report calls for a dramatic reorganization of undergraduate education to ensure that all college aspirants receive not just access to college, but an education of lasting value. The report also recommends colleges to help students become "intentional" life long learners, and to create new assessments that require students to apply their learning to the real world ${ }^{1}$. In North America, accreditation institutions (such as North Central Association) are asking academic institutions to present a method to assess student-learning outcomes in the general education courses ${ }^{2}$. The traditional grade driven method has been under scrutiny for a 
number of reasons including the student focus on grades instead of focusing on the process of learning ${ }^{3,4,5}$. Faculty members on the other hand, have a tendency to give higher grades to achieve better student evaluation ${ }^{6,7}$. A number of academic institutions in the US have moved to an outcome-based education framework to move away from the grade point average driven academic framework. Outcome-based education is a method of teaching that focuses on what students can actually do after they are taught. All curriculum and teaching decisions are made based on how best to facilitate the desired outcome. This leads to a planning process that is different from the traditional educational planning. The desired outcome is first identified and the curriculum is subsequently created to support the intended outcome $e^{8,9}$.

The impact of technology to enhance teaching and learning has been very significant in almost every subject discipline. Most faculty have become comfortable using personal productivity tools such as Microsoft Office, electronic mail, the Internet as well as a number of other applications. The 1999 National Survey of Information Technology in US Higher Education identified instructional integration as their single most significant Information Technology (IT) challenge. In fact the campus project survey indicated that assisting faculty efforts " to integrate technology into instruction" remains the single most important IT challenge confronting American colleges and universities over the next years ${ }^{10}$. In an earlier survey, the Campus Computing Project revealed that the percentage of college classes using technology continues to increase, with 44.4 percent using e-mail and 36 percent using presentation software ${ }^{11}$. However, the common use of technology in higher education classrooms does not necessarily create an environment that facilitates learning. To fully capitalize on the power of technology, instructors need to use technology to simulate real world situations, aid visualization of large complex data, facilitate collaborative activity among students, support analysis and synthesis, simulate complex environments and provide continual feedback.

A recently established academic institution in the gulf region, Zayed University, has tackled the above issues by adopting an academic framework that is outcome-based while still using the grade point average system. This academic model is a hybrid approach that can accommodate learning outcomes to measure the learning process and use grades to accommodate the classic academic system. Furthermore, the institution is designed to integrate technology in the classroom. All classrooms have network connections, data projectors, and printers. Students are required to own a notebook computer. The library electronic database can be accessed from anywhere.

A particular concern in this all female institution is how to create an environment where students are not inhibited in their daily interaction with faculty. This study shows how technology can be used as a basis to optimize student learning, encourage students to interact with faculty outside the classroom and provide students with an environment to access information from around the world. Furthermore, students take charge of their learning goals and document critical stages of their learning process in an electronic portfolio. This creates numerous opportunities for students and faculty to work together to achieve learning.

\section{Components for Optimal Learning Environment}

There are many factors that can contribute to the success of the academic environment in a university. 
At Zayed University, the main components that contribute to the creation of an atmosphere that fosters learning are:

- The wired and laptop-based campus;

- The use of technology for teaching, learning and assessing the learning outcomes;

- The electronic portfolios;

- Building of learning communities.

The above form the infrastructure that supports an environment for optimal student learning, as shown in Figure 1. In the following sections, all the components that support student learning are described.

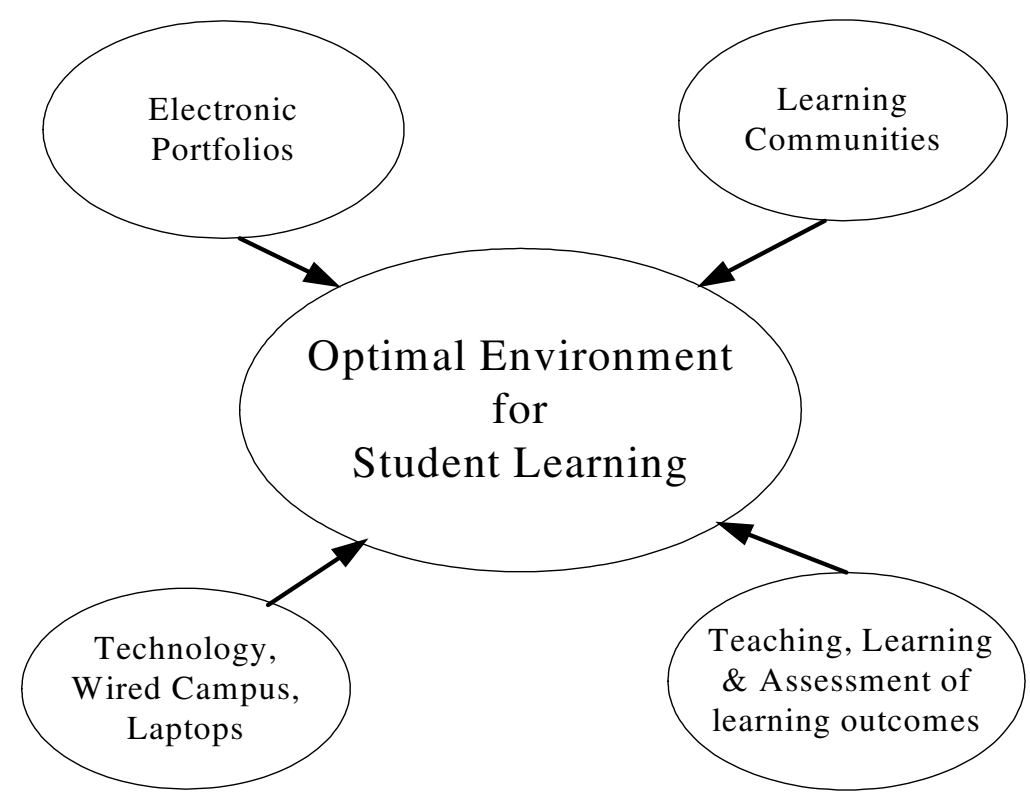

Fig.1. Components for optimal learning environment

\section{Outcome Based Framework and IS Learning Outcomes}

The outcome based academic model at Zayed University (ZU) is designed to serve as the underlying structure that guides faculty and students in the development of all programs including the Information Systems program. The ZU academic program model includes learning outcomes at all stages in the student's academic life from readiness to the majors. The curriculum at $\mathrm{ZU}$ involves three main programs:

- The readiness program;

- The general education;

- The degree majors programs.

The readiness program is a prerequisite for students to be admitted to general education. Students must satisfy competency in English, basic mathematics and Information Technology.

Students spend two years in the general education program and the last two years in a major of their choice. The college of Information Systems developed a curriculum driven by learning outcomes as well as the integration of technology in the classroom. The curriculum is designed 
to prepare students to enter the workforce and assume their place of responsibility in society. The goal of the College is to produce graduates having strong technology and communication skills as well as good understanding of business practices and work ethics.

The IS curriculum includes foundation material in: Problem-solving; Object-Oriented paradigm; File Systems; Operating Systems; Systems Architecture; Mathematics for Computing; Computer Networking; and Technical Communication. Furthermore, the curriculum includes independent study components that provide the students with the opportunity to gain in-depth knowledge of current information systems technologies, methods, and practices. The Information Systems curriculum includes five learning outcomes, which form the basis of the curriculum.

- Problem identification and analysis: Graduates will be able to recognize, define, and classify problems;

- Problem solving: Graduates will derive solutions and evaluate their success;

- Internet technologies and applications: Graduates will understand the capabilities, use, and application of information technology;

- Systems principles and practices: Graduates will demonstrate understanding of system types, structures, standards and metrics;

- Technical communication: Graduates will organize, develop, present and evaluate technical material.

All course syllabi have to explicitly identify the course contribution to achieving one or more learning outcomes. Furthermore, a web based common course syllabus is developed and posted on the intranet to facilitate student access of course content information, as well as to provide consistency and transparency of all course syllabi.

\section{Teaching at Zayed University}

Zayed University was designed to optimize its teaching environment and to make learning both spontaneous and enjoyable. Classrooms are designed to accommodate no more than 20 students. The university requires all of its students to own a laptop computer and all classrooms are wired to allow students and faculty simultaneous access to the intranet and the Internet. A small class size of 10-1 average student-instructor ratio allows instructors to dedicate more time to each student. Instructional technology is widely used in the university and students use electronic mail as well as the Internet on a daily basis. All of the above components offer the optimal conditions to create an atmosphere that facilitates and encourages student learning.

Instructors at $\mathrm{ZU}$ are expected to use technology in the classroom to make learning more interesting and challenging for students. Within such an environment, instructors can move away from the traditional static lecturing process to one where students are engaged and participate in the classroom. Students become active rather than passive learners in the classroom as well as outside the classroom. Therefore students are able to acquire and share knowledge as well as pursue their own learning goals.

Given such an environment, educators can encourage a diversity of outcomes rather than insist on one particular "right" answer. Educators can evaluate learning in multiple ways, instead of relying predominately on traditional paper and pencil tests. Most importantly, both teachers and students can move away from pursuing individual efforts to being part of learning teams. Some 
instructors on the other hand have misgivings about such environments because active learning is not always a neat process, as students engaged in such a process might create busy, noisy, and messy classrooms. This may be a problem for some educators, students however may benefit from such an environment where they are able to express themselves in a free unstructured environment

Most of the time, activities and learning environments are carefully guided and structured so learners are fully engaged in their learning. Students must learn that exploration doesn't mean just running around doing what they want. Educators must recognize that if students are investigating and asking questions, writing about what they're learning, and doing those things in an authentic context, then they are learning to access, analyze and retain information actively. Currently, two self-learning modes have been incorporated into the IS curriculum, supervised self-learning mode and supervised teamwork mode. These learning modes enable students to research a topic of their particular interest in Information Systems under the guidance and supervision of a faculty member.

\section{Building Learning Communities to Foster Learning}

The notion of using community as a place for learning builds on the change in paradigm from "teaching" to "learning". In fact, learning communities can generate a positive learning experience for college and university students, as engaging in social interactions can promote critical thinking and social competency ${ }^{12}$. Currently, the concept of "wired" learning communities is perhaps most prominent in distance education. It has been applied to the formally structured classroom settings in distance education. Moreover, learning communities are used to address the issue of how best to design and conduct online programs that foster social interactions among learners who are physically separated ${ }^{13}$.

The learning community's concept can also be used in cases were students are not able or willing to meet others but would rather use electronic means to communicate and interact. In fact, many students at Zayed University prefer the use of electronic mail and electronic bulletin boards as they allow them to communicate with each other any time and anywhere. The use of electronic mail also allows students who are in different places to communicate with their instructors and collaborate with other students at their convenience. Furthermore, the use of synchronous communication applications, like chat rooms, is very popular among students for developing social relations as the real-time nature of the chat room allows for spontaneous comments and student expression. Currently, students use this mode of communication primarily at the social level. The use of chat rooms for non-academic purposes during class time is becoming an issue in the university.

The concept of using chat rooms for an environment where students cooperate to solve academic problems is quite new at Zayed University. It needs to be further explored as it has the potential to facilitate discussion for learning. On the other hand faculty members can play a critical role as advisors and mentors in this environment. However, experience has shown that most faculty members are not interested in participating in chat room sessions for a number of reasons, including being cautious and having time constraints. Faculty members actually prefer asynchronous electronic methods of communication. 
The wired campus at Zayed University has created an environment that resulted in building communities that include students, faculty members, other members of the university, and individuals from the outside world. Social interactions among students in a community setting play a crucial part in promoting positive learning processes. Faculty members on the other hand need to encourage students to interact and be active in discussion groups and foster learning communities. In fact, learning communities have the potential to:

$\checkmark$ Provide a venue where information, ideas, and knowledge are shared and constructed;

$\checkmark$ Provide a learning structure for reflection and critical thinking;

$\checkmark$ Integrate multiple learning perspectives;

$\checkmark$ Create strong commitment to achieve common goals;

$\checkmark$ Provide positive impacts on learning.

\section{Learning Outcome Assessment and e-Portfolio}

The purpose of outcome-based learning assessment is to improve the quality of learning and teaching in the College of Information Systems. It is based on three fundamental principles:

$\checkmark$ Student learning is the focus in the classroom;

$\checkmark$ Students must be able to apply their learning beyond the classroom;

$\checkmark$ Students should become effective, independent, lifelong learners as a result of their educational experience.

Assessment of the Learning Outcomes addresses these principles by allowing students to demonstrate what they have learned. In the development process they engage in synthesis, documentation, self-assessment, and reflection on their learning experiences. The College requires students to track and provide evidence of their significant learning experiences. To facilitate this process, students take special courses to learn how to collect pieces of evidence selected from classroom projects and out-of-class activities.

Students provide evidence of their achievement by creating an electronic portfolio showing their learning experiences. Each student's electronic portfolio is a collection of critical components of her work, which allows her to demonstrate academic achievement and personal growth, as well as record her progress over time. Moreover, the electronic portfolio allows each student to see the relationships between various educational experiences (curricular and extracurricular) and represents samples of her best work. Portfolios also contain explanations of how those samples demonstrate achievement of the university's learning expectations. Students are also required to write an essay to reflect on their learning experiences, in which they explain how they substantiate the level of achievement of a particular learning outcome. In summary, the electronic portfolio is a collection of student work that:

$\checkmark$ Allow students to demonstrate academic achievement and personal growth and record their progress over time;

$\checkmark$ Allows them to see the relationships between educational experiences, curricular and extracurricular;

$\checkmark$ Represents some of the best samples of their work, as well as an explanation of how those samples demonstrate their achievement of the university's learning expectations. 
During their final academic year, students are expected to present an oral defense of their abilities to an assessment panel. The assessment panel requires students to discuss their development in the university learning outcomes, present pieces of evidence representing their best work, a reflection on the outcome achievements, and a statement of how they have satisfied the college requirements. At the end of the presentation, the assessment panel provides oral and written feedback (assessment report) to students regarding their developmental level in each learning outcome. The assessment report will become part of the student's record. The College then uses the assessment results to determine each student's degree of preparation for the internship. If the results indicate the need for further preparation, an individualized learning plan will be developed for the student.

\section{Conclusion}

In this paper, a new learning environment that uses technology as a fundamental basis is presented. Technology and the wired campus are used to create an environment that facilitates and enhances student learning. In addition, students are required to own a laptop computer. This environment also include the effective use of outcome driven IS curriculum, the student electronic portfolios, and the building of learning communities. Technology is effectively used to encourage student participation and interaction inside and outside of the classroom. Students have the option to use tools such as electronic mail, Blackboard, Internet and the Intranet as well as shared network drives for communication and information access and exchange. Students are responsible for the development of their electronic portfolios, which includes their most important learning experiences in the college, and use the university shared drives to store their achievements. In fact, by using technology students can easily keep track of, archive and update their most significant achievements. Furthermore, faculty has easy access to students' portfolios and hence can easily provide them with feedback and guidance online. The technology-based campus creates an environment that fosters group interaction and allows students and faculty to build learning communities. Faculty can join these communities to integrate multiple learning perspectives as well as provide guidance and learning structures where reflection and critical thinking are encouraged. This new learning environment has resulted in a less inhibited student body where technology is used extensively to interact with other students, faculty members, and the outside community to seek and create knowledge. It is anticipated that this environment will encourage students to become independent lifelong learners.

\section{References}

1. Greater Expectation: A new Vision for Learning as a Nation Goes to College (2002), National Panel, Published by Association of American Colleges and Universities, 2002. http:// www.aacu.org

2. North Central Association. http://www.ncacihe.org/

3. Darnell, J. H., What does an "A" Tell Us About Students Today. Proceedings of the 2001 ASEE Annual Conference \& Exposition, Albuquerque, New Mexico, June 24-27, 2001. 
4. Ghaddar, N., Moukalled, F., American Grade Inflation Demeaning Overseas Good Students: "Experience at the American University in Beyrut". Proceedings of the 2001 ASEE Annual Conference \& Exposition, Albuquerque, New Mexico, June 24-27, 2001

5. Manhire, B. The Current Status of Academic Standards in engineering Education at Ohio University. Proceedings of the 2001 ASEE Annual Conference \& Exposition, Albuquerque, New Mexico, June 24-27, 2001

6. Mansfield, H., Grade Inflation: It's time to face the facts, The Chronicle Review, April 6, 2001. http://chronicle.com/free/v47/i30/30b02401.htm)

7. Wilson, B., The Phenomenon of Grade Inflation in Higher Education, National Forum, Fall 2000. http://www.nas.org/print/print/wil_pkp_fal99.pdf

8. Fitzpatrick, K., Leadership challenges of outcome-based education. Education Digest, 60 (January), 13-16, 1995.

9. Furman, G., Outcome-based education and accountability. Education and Urban Society, 26 (4), 417-437, 1994.

10. The 1999 National Survey of Information Technology in US Higher Education. The Campus Computing Project October 1999. http://www.campuscomputing.net

11. Green, K.C., Campus Computing 1998, the Ninth National Survey of Desktop Computing and Information in Higher Education (Encino, Calif. The Campus Computing Project, February 1999).

12. Manhire, B., Emery, G.A., Mould, D.H., Noland, C.M. Ohio University's Global Learning Community. Proceedings of the 2001 ASEE Annual Conference \& Exposition, Albuquerque, New Mexico, June 24-27, 2001.

13. Rovai, A. Building Sense of Community at a Distance. International Review of Research in Open and Distance Learning, 3(1), Jun 2002, http://www.irrodl.org/content/v3.1/rovai.html.

\section{Biography}

\section{AZZEDINE LANSARI}

Azzedine received a PhD in Biomedical Engineering from North Carolina State University in 1992. From $1992-$ 1998, he was a senior researcher at MANTECH, NC. Since 1998, he has been an Assistant Professor at Zayed University. His research interests include systems modeling, educational technology and curriculum design in Information Systems. His teaching interests include Instructional Technology and statistical modeling.

\section{AKRAM AL-RAWI}

Akram is a Sun certified Java Programmer and a Professor of CIS at Zayed University, UAE. He has worked at several academic institutions of which the last two were the University of Missouri-Columbia and Columbia College, MO. His teaching interests include programming languages, logic design, and computer architecture. His research interests include computer simulation, web-caching architecture, and curriculum design.

\section{FAOUZI BOUSLAMA}

Faouzi received a PhD degree in Electronic Engineering from Shizuoka University, Japan in 1992. From 1992-1994, he was a researcher at Toshiba Co., Tokyo. From 1994-2000, he was Associate Professor of Information Systems, Hiroshima City University, in Japan. He joined Zayed University in August 2000 as an Associate Professor of Information Systems. His research interests include Neural Networks, Fuzzy Logic and Curriculum Design. 